\title{
Challenges and Constraints in Irrigation and Drainage Development: A World-Wide View
}

\author{
Marco Medici1, Daniele De Wrachien² \\ ${ }^{1}$ Department of Industrial Engineering, University of Parma, Parma, Italy \\ ${ }^{2}$ Department of Agricultural and Environmental Sciences, University of Milan, Milan, Italy \\ Email: daniele.dewrachien@unimi.it
}

Received 7 April 2016; accepted 29 May 2016; published 1 June 2016

Copyright (C) 2016 by authors and Scientific Research Publishing Inc.

This work is licensed under the Creative Commons Attribution International License (CC BY). http://creativecommons.org/licenses/by/4.0/

(c) ()

\begin{abstract}
In order to increase food production it is necessary to better understand all the factors underlying short term operations and long term strategies that lead to improve food security. In this regard any good effect deriving from agricultural research is strictly connected to a more accurate estimation of crops resources requirements, to major improvements in the use of irrigation and drainage systems, to a better understand of climatic variability. All the variables involved show strong dependency on both place and time. The failing of past, present and future systems can be essentially attributed to poor agricultural research planning, to incorrect agricultural systems design and resource allocation and to a not complete capacity to cope with short and long-term global climatic behavior.
\end{abstract}

\section{Keywords}

Challenges and Constraints, Irrigation and Drainage Development

\section{Introduction}

Irrigated agriculture is considered a key element in order to reach development objectives of achieving sustainable food security especially in developing countries. Especially as we are faced with the prospect of global population growth; the present world population of 6 billion will reach 8 billion by 2025 and 9.4 billion by 2050 [1] [2]: in this context, 8.2 billion will live in developing countries, of which 3 billion will be located in arid and semiarid environments.

In order to increase food production, it is necessary to better understand all the factors underlying short term operations and long term strategies that lead to improve food security. In this regard any good effect deriving from agricultural research is strictly connected to a more accurate estimation of crops resources requirements, to 
major improvements in the use of irrigation and drainage systems, to a better understand of climatic variability. All the variables involved show strong dependency on both place and time. The failing of past, present and future systems can be essentially attributed to poor agricultural research planning, to incorrect agricultural systems design and resource allocation and to a not complete capacity to cope with short and long-term global climatic behavior.

\section{Development in Irrigation and Drainage}

Of the world's total cultivated area ( 1.5 billion ha) over the $73 \%$ is nowadays agriculturally exploited with no water management system and it is responsible for $40 \%$ of crop output, while irrigated land and drainage facilities occupy roughly 270 million ha (18\%) and 130 million ha ( 9\%), being responsible for, respectively, 45\% and $15 \%$ of crop output [3] [4]. However, despite its high intrinsic yield potential, irrigated agriculture it is now increasing at very slow rate, and this is due to many factors, including, among all, the significant slowdown in monetary investments, the loss of irrigated areas due to bad soil management, and urban encroachment.

In rainfed areas, that represent the largest majority of agricultural realities, yields of crops productivity vary dramatically to rainfall variability, which can be seen as the most significant natural variable. Some minimal improvements for rainfed agriculture can be at least achieved with improvements in water harvesting and watershed management. This is a current challenge for several humid and semiarid areas like northeastern South America, Sub-Saharan Africa (SSA), India and central Asian countries, each of them characterized by particular social, economic and environmental characteristics. For example, the general data of annual rainfall between 1961-1990 over Nigeria shows how the rainfall range in the humid south zone is triple with respect to the drier north areas, showing how the rainfall is in this case considerably affected by latitude [5]. This huge climatic variability is associated to high risk in crop production. Local farmers need risk reducing information at first, more than soil or crop management technologies.

In India about two third of the total rainfed area is arid and also it is characterized by the highest density of population compared to other arid regions at the same latitude. Also these regions are characterized by a high variability in rainfall: normally water harvesting is considered the best-suited solution, but after long drought periods groundwater becomes the only one source of water in most villages [6]; periodically digging new wells and ponds is a common activity. In this context modern irrigation systems can be an intelligent solution for a country that already experienced the so called green revolution.

In some areas worldwide spread the rainfall can be sufficient for a period but short droughts and low productivity may happen as results of low water holding capacity of the soil. A substantial productivity loss attributable to soil degradation was estimated in SSA [2]. In this regard soil management technologies must be developed and adopted, being able to address the issue of enhancing/restoring soil structure, adopting conservation tillage, adopting efficient methods of water harvesting.

Generally important information and appropriate technologies already exist but often they are under-utilized due to policy and technology transfer constraints: new technologies that do not rely mainly on local sources of inputs are often associated to failures. At this regard attempts to introduce infrastructure dependent and irrigation based technologies in Africa did not lead to success [7] [8].

A substantial effort need to be placed on resource management research about rainfed systems, timely and reliable climate forecast, and also intensive production systems. The share of irrigated and drained areas in food production will have to increase, and installing new facilities or modernizing existing systems, in order to increase crop yields, will be necessary.

\section{The Role Played by Climate Change}

Current scientific research is focused on the enhanced greenhouse effect as the most likely cause of climate change in the short-term [9]. Local scenarios of future climatic conditions have been proposed to provide quantitative assessments about hydrologic results. These scenarios can be classified into three groups: hypothetical scenarios, climate scenarios based on general and regional circulation models (GCMs and RCMs), and scenarios based on reconstruction of past eras (paleo-climatic reconstruction) [10]. The scenarios of the second group have been widely utilized to reconstruct seasonal conditions of the change in temperature, precipitation and potential evapotraspiration at basin scale over the next century. They are complex three-dimensional computer-based models of the atmospheric circulation, which provide details of theoretical changes in regional climates for any 
part of the Earth. The standard approach has been to run the model with a nominal "pre-industrial" atmospheric $\mathrm{CO}_{2}$ concentration (the control run) and then to rerun the model with doubled (or sometimes quadrupled) $\mathrm{CO}_{2}$ (the perturbed run). This approach is known as "the equilibrium response prediction".

However, current results are not sufficiently reliable, being sometimes even in disagreement with empirical observations. Several state-of-the-art GCMs, greenhouse models in particular, have large uncertainties in defining climate scenarios; at this regard the dominant role of cumulus convection requires that warming in the tropical area upper troposphere has to be at least the double with respect to the surface; however empirical measurements deny it [11] [12]. What is known is that forecasts of anthropogenic global climate change have been unreliable so far, and in general, present climate alarmists respond to the evidence of the relatively warm recent decade. Yet, considering also that heat transferred between deep layers of the troposphere and the ocean surface occurs over a time scale from years to centuries, this demonstrates nothing in terms of temperature trends [13] [14].

\section{Concluding Remarks}

- A substantial effort need to be placed on resource management research about rainfed systems in developing countries. The share of irrigated and drained areas in food production will have to increase, and installing new facilities or modernizing existing systems will be necessary. Appropriate technologies already exist but often they are under-utilized due to policy and technology transfer constraints. New technologies have to rely on local sources of inputs. It is also necessary to reduce vulnerability to environmental changes providing local farmers of higher incomes and more suitable technology.

- An integrated approach to irrigation and drainage systems development is necessary. There is a strong need for high quality and innovative research in soil science; efforts should focus on efficient use of fresh water resources and limit soil degradation.

- Nowadays the disturbing news about global warming need to be locally verified in order to perform reliable analysis. Empirical evidences demonstrate how the anthropogenic contribution to recent warming is surprisingly smaller than expected. On the other hand climate will always change as long as our planet will have a fluid envelope: attempts from scientists should focus simple approaches in order to reduce present persistent uncertainty and establish estimates of climate sensitivity that are fully focused and testable.

\section{References}

[1] De Wrachien, D. and Feddes, R. (2003) Drainage and Land Reclamation in a Changing Environment: Overview and Challenges. Proceeding of the International Conference on Land Reclamation and Water resources Development, Mantua.

[2] Lal, R. (2000) Soil Management in the Developing Countries. Soil Science, 165, 57-72. http://dx.doi.org/10.1097/00010694-200001000-00008

[3] Schultz, B. (2001) Irrigation Drainage and Flood Protection in a Rapidly Changing World. Irrigation and Drainage, 50, 4. http://dx.doi.org/10.1002/ird.35

[4] Smedema, L.K. (2000) Global Drainage Needs and Challenges. The Role of Drainage in the Today's World. Proceedings of the 8th International Workshop on Drainage, New Delhi.

[5] Jagtap, S.S. and Chan, A.K. (2000) Agrometeorological Aspects of Agriculture in the Sub-Humid and Humid Zones of Africa and Asia. Agricultural and Forest Meteorology, 103, 59-72. http://dx.doi.org/10.1016/S0168-1923(00)00117-9

[6] Singh, R.B. and Kumar, A. (2014) Vulnerability of Agriculture to Climate Change in Arid Regions: A Case Study of Western Rajasthan, India. Vulnerability of Land Systems in Asia, 77-90. http://dx.doi.org/10.1002/9781118854945.ch6

[7] Goldman, R.H. and Block, S. (1993) Proceedings from the Symposium on Agricultural Transformation in Africa, ARAP II. Technical Report No. 137, Abt Associates, Cambridge.

[8] Garb, Y. and Friedlander, L. (2014) From Transfer to Translation: Using Systemic Understandings of Technology to Understand Drip Irrigation Uptake. Agricultural Systems, 128, 13-24. http://dx.doi.org/10.1016/j.agsy.2014.04.003

[9] Environmental Protection Agency (EPA) (2013) Overview of Greenhouse Gases. Carbon Dioxide Emissions. http://www.epa.gov/climatechange/ghgemissions/gases/co2.html

[10] De Wrachien, D. and Goli, M. (2015) Global Warming Effects on Irrigation Development and Crop Production: A World-Wide View. Agricultural Sciences, 6, 7. http://dx.doi.org/10.4236/as.2015.67071

[11] Lindzen, R.S. (2007) Taking Greenhouse Warming Seriously. Energy and Environment, 18, 937-950. 
http://dx.doi.org/10.1260/095830507782616823

[12] Douglass, D.H., Christy, J.R., Pearson, B.D. and Singer, S.F. (2008) A Comparison of Tropical Temperature Trends with Model Predictions. International Journal of Climatology, 28, 1693-1701. http://dx.doi.org/10.1002/joc.1651

[13] Tsonis, A.A., Swanson, K. and Kravtsov, S. (2007) A New Dynamical Mechanism for Major Climate Shifts. Geophysical Research Letters, 34, L13705. http://dx.doi.org/10.1029/2007gl030288

[14] Lindzen, R. (2011) A Case against Precipitous Climate Action. Energy and Environment, 22, 747-751. http://dx.doi.org/10.1260/0958-305X.22.6.747 